\title{
Optimal design of reinforced concrete beams for rectangular sections with straight haunches
}

Arnulfo Luévanos-Rojas (Main and Corresponding Author) Instituto de Investigaciones Multidisciplinaria, Universidad Autónoma de Coahuila Blvd. Revolución No, 151 Ote, CP 27000, Torreón, Coahuila (Mexico)

arnulfol_2007@hotmail.com

\section{Sandra López-Chavaría}

Instituto de Investigaciones Multidisciplinaria, Universidad Autónoma de Coahuila Blvd. Revolución No, 151 Ote, CP 27000, Torreón, Coahuila (Mexico)

sandylopez5@hotmail.com

\section{Manuel Medina-Elizondo}

Instituto de Investigaciones Multidisciplinaria, Universidad Autónoma de Coahuila Blvd. Revolución No, 151 Ote, CP 27000, Torreón, Coahuila (México)

drmanuelmedina@yahoo.com.mx

\section{Vitaliy V. Kalashnikov}

Facultad de Ciencias Física y Matemáticas, Universidad Autónoma de Nuevo León Av. Universidad S/N, Cd. Universitaria, San Nicolás de los Garza, Nuevo León (Mexico) kalashnikov_de@yahoo.de

Manuscript Code: 1517

Date of Acceptance/Reception: 16.03.2020/19.06.2019

DOI: 10.7764/RDLC.19.1.90-102

\section{Abstract}

Objective of this research is to present a mathematical model for optimal design of rectangular cross-section beams with straight haunches under the criterion of minimum cost considering the concrete cost and reinforcing steel cost, and taking into account the equations of the regulation ( $\mathrm{ACl}$ 318S-14). This model presents the equations for a uniformly distributed load and a concentrated load located anywhere on the beam. Two examples are developed by the proposed model, one for uniformly distributed load and another for concentrated load showing the best solution for each case. The results show the following: a) The prismatic beams for uniformly distributed load have a total cost of the $8 \%$ greater, a total volume and a total weight of the $9 \%$ greater with respect to the non-prismatic beams; b) The prismatic beams for concentrated load have a total cost, a total volume and a total weight of the $6 \%$ greater with respect to the non-prismatic beams. The main conclusions are: For a smaller $b$ width the optimal design for both models is presented. The non-prismatic beams are more economical, also these have less volume and less weight with respect to prismatic beams.

Keywords: Optimal design, straight haunches, minimum cost, rectangular cross-section beams, uniformly distributed load, concentrated load.

\section{Introduction}

The beams of reinforced concrete with straight or parabolic haunches have been used in different types of structures as buildings and bridges. The beams with haunches (non-prismatic beams) have the following advantages with respect to prismatic beams: a) The rigidity increases, b) The relative displacements decrease, c) The use of concrete and reinforcing steel is more efficient, d) The architectural forms are more attractive, e) Facilitate the placement of electrical, hydraulic, air conditioning and sanitary installations in the building.

The conventional procedure for the project of reinforced concrete beams has been to estimate the dimensions of the beam cross section, and to calculate the necessary steel area, in order to come to a solution. However, there are other solutions for the same beam. Through optimization techniques, it is possible to determine the section dimensions, steel areas and other beam parameters which minimize costs, meeting safety criteria. Thus, through optimization, an optimal solution is found.

The design common practice is to provide the necessary reinforcement by flexural at the ends of the beams with haunches (top), extending at a distance equal to the anchoring length and development required to guarantee its nominal strength moment at the ends. Therefore, the longitudinal reinforcement is usually located in the zone of the haunches in top part, leaving the transition zone between the haunches and the intermediate prismatic section with 
reinforcement in below part. This practice is based on the diagrams of bending moments of beams with straight or parabolic haunches in its ends under gravitational and live loads, where the bending moments increase at the ends and decrease along the longitudinal axis of the beam. This solution is well known for quite some time (Guldan, 1956).

The mathematical models of beams with haunches have aroused great interest among structural analysis researchers. Most of the articles and books present the factors for fixed end moments, carry-over factors and stiffness factors used in the structural analysis matrix methods (Guldan, 1956; Portland Cement Association, 1958; Just, 1977; Schreyer, 1978; Medwadowski, 1984; Brown, 1984; Tena-Colunga, 1996; Shooshtari \& Khajavi, 2010; Yuksel, 2012; LuévanosRojas, 2015; Luévanos-Rojas et al., 2016a, b; Luévanos-Soto \& Luévanos-Rojas, 2017).

The papers for optimal design of rectangular reinforced concrete beams are: Sensitivity analysis and optimum design curves for the minimum cost design of singly and doubly reinforced concrete beams applied the Lagrangian Multiplier Method (LMM) to obtain the minimum cost design for both cases (Ceramic \& Fryer, 2000); Cost optimization of singly and doubly reinforced concrete beams with EC2-2001 taking to account the stress-strain diagrams (Barros et al., 2005); Cost optimization of doubly reinforced rectangular beam section for simply supported beams under uniformly distributed and concentrated load (Bhalchandra \& Adsul, 2012); Optimal design of reinforced concrete beams: A review of the available literature for minimum cost or weight (Rahmanian et al., 2014); Numerical experimentation for the optimal design of reinforced rectangular concrete beams for singly reinforced sections is presented to obtain the minimum cost and minimum weight (Luévanos-Rojas, 2016); Design optimization of reinforced concrete beams by optimization techniques (Chutani \& Singh, 2017); Optimization of singly reinforced RC beams to obtain the minimum cost (Thomas \& Arulraj, 2017); A study on cost optimized structural design of reinforced concrete beams using optimization techniques (Hisham-Ajmal, 2017); Optimization of reinforced concrete beams for rectangular sections with numerical experiments are presented for simply reinforced beams and doubly reinforced beams (Luévanos-Rojas, et al., 2018). These articles presented are just some of the studies on the topic.

Therefore, the review of the literature clearly shows that there is no close relationship with the subject for the optimal design of reinforced concrete beams for rectangular sections with straight haunches that is addressed in this document.

This document presents a mathematical model for the optimal design of rectangular cross-section beams with straight haunches (General case) using the minimum cost criterion taking into account the cost of concrete and the cost of reinforcing steel, and taking into account the equations of the code $(\mathrm{ACl} 318 \mathrm{~S}-14)$ that is the novelty of this investigation. Two examples are developed by the proposed model, one for uniformly distributed load and another for concentrated load showing the best solution for each case, and the advantages of the non-prismatic beams are presented on the prismatic beams, and the two examples are shown by means of numerical experiments.

\section{Formulation of the proposed model}

Methodology

The general formulation of an optimization problem is shown below:

Objective function:

Subject to:

$$
\text { Minimize: } f(x)
$$

$$
\begin{gathered}
h_{j}(x)=0, j=1, \ldots, m \\
g_{k}(x)=0, k=1, \ldots, p \\
x_{i}^{\min } \leq x_{i} \leq x_{i}^{\max }, i=1, \ldots, n
\end{gathered}
$$

Figure 1 shows a beam of rectangular cross section with straight haunches subjected to two different types of loads and moments at their ends resulting from structural analysis.

Figure 1. Rectangular non prismatic beam subjected to two types of loads: (a) Uniformly distributed load; (b) Concentrated load located anywhere on the beam.

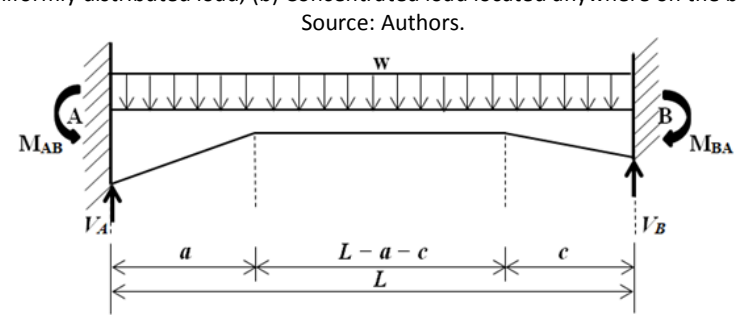




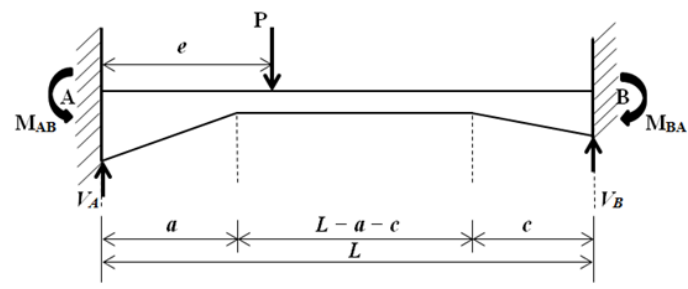

(b)

where: $V_{A}$ is the shear force in support $A, V_{B}$ is the shear force in support $B, M_{A}$ is the moment in support $A, M_{B}$ is the moment in support $B, w$ is the uniformly distributed load, $L$ is the length of the beam, $P$ is the concentrated load, e is the distance where the concentrated load is located from support $A$, $a$ is the horizontal distance of the straight haunches in support $A, c$ is the horizontal distance of the straight haunches in support $B$.

Table 1 shows the main mechanical elements to which the beam is subjected for two types of loads as a function of the bending moments that act on the ends, these result from the structural analysis.

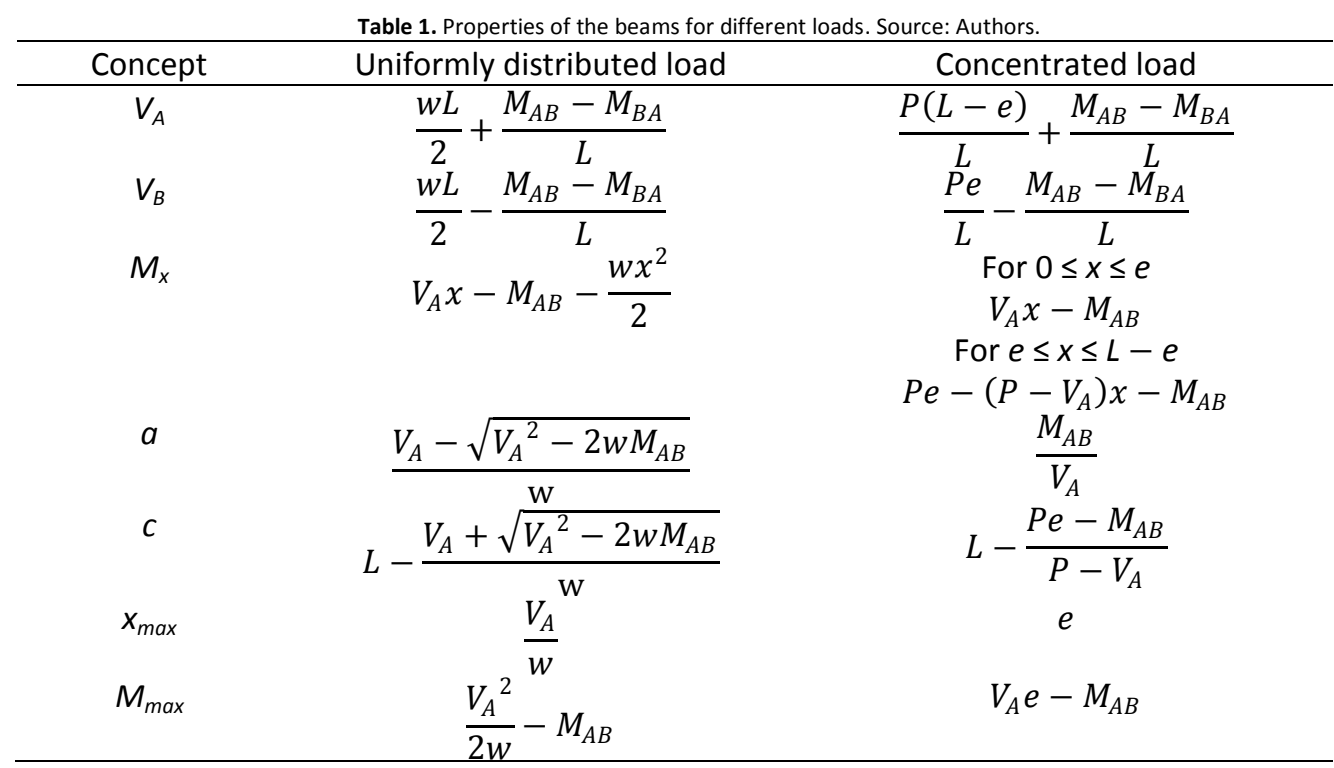

where: $M_{x}$ is the moment at a distance " $x$ " measured from support $A, M_{\max }$ is the positive maximum moment, $x_{\max }$ is the distance where the positive maximum moment is located from support $A$.

The equations presented by the code are (ACI 318S-14, Luévanos-Rojas, 2016):

$$
\begin{gathered}
M_{u}=\varnothing_{f} b d^{2} \rho f_{y}\left(1-\frac{0.59 \rho f_{y}}{f_{c}^{\prime}}\right) \\
\rho=\frac{A_{s}}{b d} \\
\rho_{b}=\frac{0.85 \beta_{1} f_{c}^{\prime}}{f_{y}}\left(\frac{600}{600+f_{y}}\right) \\
0.65 \leq \beta_{1}=\left(1.05-\frac{f_{c}^{\prime}}{140}\right) \leq 0.85 \\
\rho_{\max }=0.75 \rho_{b} \\
\rho_{\min }=\left\{\begin{array}{c}
0.25 \sqrt{f_{c}^{\prime}} \\
\frac{f_{y}}{1.4} \\
M_{u}
\end{array}=\emptyset_{f} M_{n}\right.
\end{gathered}
$$


where: $M_{u}$ is the maximum factorized moment, $\varnothing_{f}$ is the reduction factor of resistance by bending and its value is 0.90 , $b$ is the base of the rectangular section, $d$ is the effective depth, $A_{s}$ is the steel area in tension, $\rho$ is the percentage of reinforcing steel and is obtained by $A_{s} / b d, B_{1}$ is the factor that relates the depth of the rectangular equivalent stress block of compression to the depth of the neutral axis, $f_{y}$ is the specified yield strength of the reinforcing steel, $f_{c}^{\prime}$ is the compressive strength specified at 28 days, $M_{n}$ is the nominal bending moment, $\rho_{\max }$ is the maximum percentage of reinforcing steel, $\rho_{\min }$ is the minimum percentage of reinforcing steel.

Some specifications of the code mention the following ( $\mathrm{ACl} 318 \mathrm{~S}-14)$ : At least $1 / 3$ of the total tensile reinforcement in the support provided to resist negative moment must have an embedded length beyond the inflection point, not less than $d, 12 d_{b}$ or $L / 16$, whichever is greater.

Figure 2 shows the profile of the beam to observe the dimensions and the main reinforcement in general form.

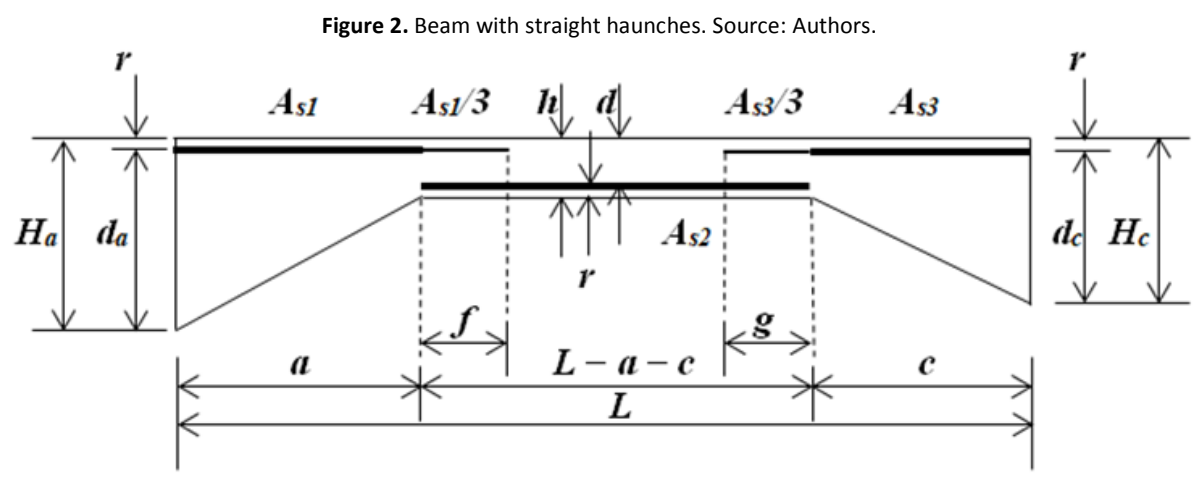

The total cost function of the $C_{t}$ beam is composed of the cost of the reinforcing steel $C_{s}$ plus the cost of the $C_{c}$ concrete (the cost of the formwork is not considered by limitation of the study). The total cost is:

$$
C_{t}=C_{s} V_{s}+C_{c} V_{c}
$$

where: $V_{s}$ is the volume of reinforcing steel, $V_{c}$ is the volume of concrete.

The volume of reinforcing steel is:

$$
V_{s}=\frac{A_{s 1}(3 a+f)}{3}+A_{s 2}(L-a-c)+\frac{A_{s 3}(3 c+g)}{3}
$$

The volume of concrete is:

$$
V_{c}=b\left[h L+\frac{a\left(H_{a}-h\right)}{2}+\frac{c\left(H_{c}-h\right)}{2}\right]-\left[\frac{A_{s 1}(3 a+f)}{3}+A_{s 2}(L-a-c)+\frac{A_{s 3}(3 c+g)}{3}\right]
$$

where: $A_{s 1}$ is the reinforcing steel area in the haunches of the support $\mathrm{A}, A_{s 2}$ is the reinforcing steel area in the central part, $A_{s 3}$ is the reinforcing steel area in the haunches of the support $\mathrm{B}, H_{a}$ is the height of the beam in support $\mathrm{A}, h$ is the height of the beam in the central part, $H_{c}$ is the height of the beam in support $B, f$ is the distance provided by the $\mathrm{ACl}\left(d, 12 d_{b} \circ L / 16\right.$, whichever is greater) for the support $\mathrm{A}, g$ is the distance provided by the $\mathrm{ACl}\left(d, 12 d_{b} \circ L / 16\right.$, whichever is greater) for the support B.

The heights of the beam are obtained by:

$$
\begin{aligned}
H_{a} & =d_{a}+r \\
h & =d+r \\
H_{c} & =d_{c}+r
\end{aligned}
$$

Substituting Eqs. (13), (14) and (15) into Eq. (12) is obtained:

$$
V_{c}=b\left[(d+r) L+\frac{a\left(d_{a}-d\right)}{2}+\frac{c\left(d_{c}-d\right)}{2}\right]-\left[\frac{A_{s 1}(3 a+f)}{3}+A_{s 2}(L-a-c)+\frac{A_{s 3}(3 c+g)}{3}\right]
$$


Now, substituting Eqs. (11) and (16) into Eq. (10) is obtained the general equation of the total cost:

$$
\begin{aligned}
C_{t}=C_{s}\left[\frac{A_{s 1}(3 a+f)}{3}+A_{s 2}(L-a-c)+\frac{A_{s 3}(3 c+g)}{3}\right] \\
+C_{c}\left\{b\left[(d+r) L+\frac{a\left(d_{a}-d\right)}{2}+\frac{c\left(d_{c}-d\right)}{2}\right]\right. \\
\left.-\left[\frac{A_{s 1}(3 a+f)}{3}+A_{s 2}(L-a-c)+\frac{A_{s 3}(3 c+g)}{3}\right]\right\}
\end{aligned}
$$

Substituting $\alpha=C_{s} / C_{c}$ into Eq. (17), and the objective function is presented as follows:

$$
\begin{aligned}
C_{t}=C_{c}\{b[(d+ & \left.r) L+\frac{a\left(d_{a}-d\right)}{2}+\frac{c\left(d_{c}-d\right)}{2}\right] \\
& \left.+(\alpha-1)\left[\frac{A_{s 1}(3 a+f)}{3}+A_{s 2}(L-a-c)+\frac{A_{s 3}(3 c+g)}{3}\right]\right\}
\end{aligned}
$$

The constraint functions are presented in general form as follows:

$$
\begin{gathered}
\frac{M_{A B}}{\emptyset_{f} f_{y}}=d_{a} A_{s 1}\left(1-\frac{0.59 A_{s 1} f_{y}}{b d_{a} f_{c}^{\prime}}\right) \\
\frac{M_{\text {max }}}{\emptyset_{f} f_{y}}=d A_{s 2}\left(1-\frac{0.59 A_{s 2} f_{y}}{b d f_{c}^{\prime}}\right) \\
\frac{M_{B A}}{\emptyset_{f} f_{y}}=d_{c} A_{s 3}\left(1-\frac{0.59 A_{s 3} f_{y}}{b d_{c} f_{c}^{\prime}}\right) \\
\rho_{a}, \rho, \rho_{c} \leq 0.75\left[\frac{0.85 \beta_{1} f_{c}^{\prime}}{f_{y}}\left(\frac{600}{600+f_{y}}\right)\right] \\
\rho_{a}, \rho, \rho_{c} \geq\left\{\begin{array}{c}
\frac{0.25 \sqrt{f_{c}^{\prime}}}{f_{y}} \\
\frac{1.4}{f_{y}}
\end{array}\right. \\
A_{s 1}=\rho_{a} b d_{a} \\
A_{s 2}=\rho b d
\end{gathered}
$$

Eq. (19) is obtained from the comparison of the moment that acts " $M_{A B}$ " and moment resistant in the support $A$ "Eq. (3)". Eq. (20) is found from the comparison of the moment that acts " $M_{\max }$ " and moment resistant in the central part "Eq. (3)". Eq. (21) is obtained from the comparison of the moment that acts " $\mathrm{M}_{\mathrm{BA}}$ " and moment resistant in the support B "Eq. (3)". Eq. (22) is the maximum percentage of reinforcing steel in each part of the beam "Eqs. (5) to (7)". Eq. (23) is the minimum percentage of reinforcing steel in each part of the beam "Eq. (8)". Eq. (24) is the reinforcing steel in in the support A "Eq. (4)". Eq. (25) is the reinforcing steel in in the central part "Eq. (4)". Eq. (26) is the reinforcing steel in in the support B "Eq. (4)".

It is assumed that all variables are non-negative.

where: $\rho_{a}$ is the percentage of reinforcing steel in support A, $\rho$ is the percentage of reinforcing steel in the central part and $\rho_{c}$ is the percentage of reinforcing steel in support $B$.

The total volume of beam $V_{t}$ is obtained as follows:

$$
V_{t}=b\left[h L+\frac{a\left(H_{a}-h\right)}{2}+\frac{c\left(H_{c}-h\right)}{2}\right]
$$

The total weight of the beam $W_{t}$ is found as follows:

$$
W_{t}=W_{s} V_{s}+W_{c} V_{c}
$$


where: $W_{s}$ is the weight of the reinforcing steel, $W_{c}$ is the weight of the concrete.

Substituting $\mu=W_{s} / W_{c}$ into Eq. (28), and the weight of the beam is presented as follows:

$$
W_{t}=\mu W_{c} V_{s}+W_{c} V_{c}
$$

\section{Application of the model}

In this section, two numerical examples are presented to validate the proposed model. Example 1 shows the design of a beam subjected to a uniformly distributed load. Example 2 presents the design of a beam subjected to a concentrated load. For both examples, the optimization method is used by the MAPLE-15 software to found the optimal solution, and numerical experiments are also presented for each example, fixing certain parameters.

\section{Example 1}

Design a beam subjected to a uniformly distributed load with straight haunches. The basic data are: $L=10.00 \mathrm{~m} ; w=$ $150 \mathrm{kN} / \mathrm{m} ; M_{A B}=1000 \mathrm{kN}-\mathrm{m} ; M_{B A}=1400 \mathrm{kN}-\mathrm{m}_{;}{f^{\prime}}_{c}=28 \mathrm{MPa} ; f_{y}=420 \mathrm{MPa}$ and $\alpha=90$. According to the code is considered: $r=4 \mathrm{~cm}, f=d_{a}, g=d_{c}$. Substituting $L=10.00 \mathrm{~m} ; w=150 \mathrm{kN} / \mathrm{m} ; M_{A B}=1000 \mathrm{kN}-\mathrm{m} ; M_{B A}=1400 \mathrm{kN}-\mathrm{m}$ into the equations shown in Table 1 for uniformly distributed load are obtained: $V_{A}=710.00 \mathrm{kN}, V_{B}=790.00 \mathrm{kN}, M_{x}=710 \mathrm{x}$ $-1000-75 x^{2}, a=1.72 m, c=2.25 m, x_{\max }=4.73 m, M_{\max }=680.33 \mathrm{kN}-\mathrm{m}$.

Now, substituting this information in Eqs. (18) to (26) are obtained the objective function and the constraint functions.

The objective function is:

$$
C_{t}=C_{c}\left[b\left(0.86 d_{a}+1.13 d_{c}+8.01 d+0.4\right)+29.67 A_{s 1} d_{a}+29.67 A_{s 3} d_{c}+153.21 A_{s 1}+536.11 A_{s 2}+200.68 A_{s 3}\right]
$$

Subject to:

$$
\begin{gathered}
\frac{1}{378}=d_{a} A_{s 1}\left(1-\frac{177 A_{s 1}}{20 b d_{a}}\right) \\
\frac{2041}{1134000}=d A_{s 2}\left(1-\frac{177 A_{s 2}}{20 b d}\right) \\
\frac{1}{270}=d_{c} A_{s 3}\left(1-\frac{177 A_{s 3}}{20 b d_{c}}\right) \\
\rho_{a}, \rho, \rho_{c} \leq 0.02125 \\
\rho_{a}, \rho, \rho_{c} \geq 0.00333 \\
A_{s 1}=\rho_{a} b d_{a} \\
A_{s 2}=\rho b d \\
A_{s 3}=\rho_{c} b d_{c}
\end{gathered}
$$

It is assumed that all variables are non-negative.

Table 2 shows the results fixing $b=30,40,50,60,70 \mathrm{~cm}$, and the project variables are: $A_{s 1}, A_{s 2}, A_{s 3}, d_{a}, d, d_{c}, \rho_{a}, \rho, \rho_{c}$.

Table 3 shows the results fixing $b=30 \mathrm{~cm}$, and $\rho_{a}, \rho, \rho_{c}=0.02125,0.01500,0.01000,0.00500,0.00333$, and the project variables are: $A_{s 1}, A_{s 2}, A_{s 3}, d_{a}, d, d_{c}$.

Table 4 shows the results fixing $b=30,40,50,60,70 \mathrm{~cm}$, and the project variables are: $d_{a}=d=d_{c}, A_{s 1}, A_{s 2}, A_{s 3}, \rho_{a}, \rho, \rho_{c}$.

\begin{tabular}{ccccccccccc}
\multicolumn{10}{c}{ Table 2. Fixing $b=30,40,50,60,70 \mathrm{~cm}$. Source: Authors. } \\
\hline$b$ & $A_{s 1}$ & $A_{s 2}$ & $A_{s 3}$ & $d_{a}$ & $d$ & $d_{c}$ & & $\rho_{c}$ & $\rho$ & $\rho_{t}$ \\
$c m$ & $c m^{2}$ & $c m^{2}$ & $c m^{2}$ & $c m$ & $c m$ & $c m$ & 0.00501 & $5.25 C_{c}$ \\
\hline 30 & 20.38 & 26.70 & 24.14 & 135.79 & 75.29 & 160.52 & 0.00500 & 0.01182 & 0.005 \\
40 & 23.57 & 30.83 & 27.92 & 117.45 & 65.21 & 138.85 & 0.00502 & 0.01182 & 0.00503 & $6.05 C_{c}$ \\
50 & 26.38 & 34.46 & 31.24 & 104.95 & 58.32 & 124.09 & 0.00503 & 0.01182 & 0.00503 & $6.76 C_{c}$ \\
60 & 28.92 & 37.75 & 34.25 & 95.74 & 53.24 & 113.21 & 0.00503 & 0.01182 & 0.00504 & $7.41 C_{c}$ \\
70 & 31.25 & 40.78 & 37.01 & 88.60 & 49.29 & 104.76 & 0.00504 & 0.01182 & 0.00505 & $8.01 C_{c}$ \\
\hline
\end{tabular}


Table 3. Fixing $b=30 \mathrm{~cm}$, and $\rho_{a}, \rho, \rho_{c}=0.02125,0.01500,0.01000,0.00500,0.00333$. Source: Authors.

\begin{tabular}{|c|c|c|c|c|c|c|c|c|c|c|}
\hline $\begin{array}{c}b \\
\mathrm{~cm}\end{array}$ & $\begin{array}{l}A_{s 1} \\
\mathrm{~cm}^{2}\end{array}$ & $\begin{array}{l}A_{s 2} \\
\mathrm{~cm}^{2}\end{array}$ & $\begin{array}{l}A_{s 3} \\
\mathrm{~cm}^{2}\end{array}$ & $\begin{array}{c}d_{a} \\
\mathrm{~cm}\end{array}$ & $\begin{array}{c}d \\
\mathrm{~cm}\end{array}$ & $\begin{array}{c}d_{c} \\
\mathrm{~cm}\end{array}$ & $\rho_{a}$ & $\rho$ & $\rho_{c}$ & $C_{t}$ \\
\hline 30 & 45.58 & 37.59 & 53.93 & 71.49 & 58.97 & 84.59 & 0.02125 & 0.02125 & 0.02125 & $6.04 C_{c}$ \\
\hline 30 & 37.05 & 30.56 & 43.84 & 82.33 & 67.91 & 97.43 & 0.01500 & 0.01500 & 0.01500 & $5.60 C_{c}$ \\
\hline 30 & 29.51 & 24.34 & 34.91 & 98.36 & 81.13 & 116.38 & 0.01000 & 0.01000 & 0.01000 & $5.38 C_{c}$ \\
\hline 30 & 20.38 & 16.81 & 24.11 & 135.84 & 112.05 & 160.73 & 0.00500 & 0.00500 & 0.00500 & $5.60 C_{c}$ \\
\hline 30 & 16.51 & 13.62 & 19.54 & 165.10 & 136.18 & 195.35 & 0.00333 & 0.00333 & 0.00333 & $6.05 C_{c}$ \\
\hline
\end{tabular}

Table 4. Fixing $b=30,40,50,60,70 \mathrm{~cm}$, and $d_{\alpha} d, d_{c}$ are equal (constant cross section). Source: Authors.

\begin{tabular}{|c|c|c|c|c|c|c|c|c|c|c|}
\hline $\begin{array}{c}b \\
\mathrm{~cm}\end{array}$ & $\begin{array}{l}A_{s 1} \\
\mathrm{~cm}^{2}\end{array}$ & $\begin{array}{l}A_{s 2} \\
\mathrm{~cm}^{2}\end{array}$ & $\begin{array}{l}A_{s 3} \\
\mathrm{~cm}^{2}\end{array}$ & $\begin{array}{c}d_{a} \\
\mathrm{~cm}\end{array}$ & $\begin{array}{c}d \\
\mathrm{~cm}\end{array}$ & $\begin{array}{c}d_{c} \\
\mathrm{~cm}\end{array}$ & $\rho_{a}$ & $\rho$ & $\rho_{c}$ & $C_{t}$ \\
\hline 30 & 29.45 & 19.40 & 43.18 & 98.52 & 98.52 & 98.52 & 0.00996 & 0.00656 & 0.01461 & $5.65 C_{c}$ \\
\hline 40 & 34.05 & 22.42 & 49.93 & 85.23 & 85.23 & 85.23 & 0.00999 & 0.00658 & 0.01464 & $6.51 C_{c}$ \\
\hline 50 & 38.10 & 25.09 & 55.87 & 76.18 & 76.18 & 76.18 & 0.01000 & 0.00659 & 0.01467 & $7.27 C_{c}$ \\
\hline 60 & 41.76 & 27.50 & 61.25 & 69.51 & 69.51 & 69.51 & 0.01001 & 0.00659 & 0.01469 & $7.97 C_{c}$ \\
\hline 70 & 45.13 & 29.72 & 66.19 & 64.33 & 64.33 & 64.33 & 0.01002 & 0.00660 & 0.01470 & $8.61 C_{c}$ \\
\hline
\end{tabular}

\section{Example 2}

Design a beam subjected to a concentrated load with straight haunches. The basic data are: $L=10.00 \mathrm{~m} ; P=1000 \mathrm{kN}$; $e=3.00 \mathrm{~m} ; M_{A B}=1000 \mathrm{kN}-\mathrm{m} ; M_{B A}=1400 \mathrm{kN}-\mathrm{m} ; f_{c}^{\prime}=28 \mathrm{MPa} ; f_{y}=420 \mathrm{MPa}$ and $\alpha=90$. According to the code is considered: $r=4 \mathrm{~cm}, f=d_{a}, g=d_{c}$. Substituting $L=10.00 \mathrm{~m} ; P=1000 \mathrm{kN} ; e=3.00 \mathrm{~m} ; M_{A B}=1000 \mathrm{kN}-\mathrm{m} ; M_{B A}=1400 \mathrm{kN}$ $m$ into the equations shown in Table 1 for concentrated load are obtained: $V_{A}=660.00 \mathrm{kN}, V_{B}=340.00 \mathrm{kN}, M_{x}=660 x$ -1000 for $0 \leq x \leq e, M_{x}=2000-340 x$ for $e \leq x \leq L-e, a=1.52 m, c=4.12 m, x_{\max }=3.00 m, M_{\max }=980.00 \mathrm{kN}-\mathrm{m}$.

Now, substituting this information in Eqs. (18) to (26) are obtained the objective function and the constraint functions.

The objective function is:

$$
C_{t}=C_{c}\left[b\left(0.78 d_{a}+2.06 d_{c}+7.18 d+0.4\right)+29.67 A_{s 1} d_{a}+29.67 A_{s 3} d_{c}+134.85 A_{s 1}+388.68 A_{s 2}+366.47 A_{s 3}\right]
$$

Subject to:

$$
\begin{gathered}
\frac{1}{378}=d_{a} A_{s 1}\left(1-\frac{177 A_{s 1}}{20 b d_{a}}\right) \\
\frac{7}{2700}=d A_{s 2}\left(1-\frac{177 A_{s 2}}{20 b d}\right) \\
\frac{1}{270}=d_{c} A_{s 3}\left(1-\frac{177 A_{s 3}}{20 b d_{c}}\right) \\
\rho_{a}, \rho, \rho_{c} \leq 0.02125 \\
\rho_{a}, \rho, \rho_{c} \geq 0.00333 \\
A_{s 1}=\rho_{a} b d_{a} \\
A_{s 2}=\rho b d \\
A_{s 3}=\rho_{c} b d_{c}
\end{gathered}
$$

It is assumed that all variables are non-negative.

Table 5 shows the results fixing $b=30,40,50,60,70 \mathrm{~cm}$, and the project variables are: $A_{s 1}, A_{s 2}, A_{s 3}, d_{a}, d, d_{c}, \rho_{a}, \rho, \rho_{c}$.

Table 6 shows the results fixing $b=30 \mathrm{~cm}$, and $\rho_{a}, \rho, \rho_{c}=0.02125,0.01500,0.01000,0.00500,0.00333$, and the project variables are: $A_{s 1}, A_{s 2}, A_{s 3}, d_{a}, d, d_{c}$.

Table 7 shows the results fixing $b=30,40,50,60,70 \mathrm{~cm}$, and the project variables are: $d_{a}=d=d_{c}, A_{s 1}, A_{s 2}, A_{s 3}, \rho_{a}, \rho, \rho_{c}$. 
Table 5. Fixing $b=30,40,50,60,70 \mathrm{~cm}$. Source: Authors.

\begin{tabular}{ccccccccccc}
\multicolumn{10}{c}{ Table 5. Fixing $b=30,40,50,60,70 \mathrm{~cm}$. Source: Authors. } \\
\hline$b$ & $A_{s 1}$ & $A_{s 2}$ & $A_{s 3}$ & $d_{a}$ & $d$ & $d_{c}$ & & & \\
$c m$ & $c m^{2}$ & $c m^{2}$ & $c m^{2}$ & $c m$ & $c m$ & $c m$ & $\rho_{a}$ & $\rho$ & $\rho_{c}$ & $C_{t}$ \\
\hline 30 & 20.35 & 35.15 & 24.25 & 135.97 & 84.13 & 159.87 & 0.00499 & 0.01393 & 0.00506 & $5.96 C_{c}$ \\
40 & 23.54 & 40.59 & 28.02 & 117.58 & 72.86 & 138.36 & 0.00501 & 0.01393 & 0.00506 & $6.87 C_{c}$ \\
50 & 26.35 & 45.38 & 31.35 & 105.06 & 65.17 & 123.70 & 0.00502 & 0.01393 & 0.00507 & $7.68 C_{c}$ \\
60 & 28.89 & 49.71 & 34.35 & 95.83 & 59.49 & 112.88 & 0.00502 & 0.01393 & 0.00507 & $8.41 C_{c}$ \\
70 & 31.22 & 53.69 & 37.12 & 88.67 & 55.08 & 104.48 & 0.00503 & 0.01393 & 0.00507 & $9.09 C_{c}$ \\
\hline
\end{tabular}

Table 6. Fixing $b=30 \mathrm{~cm}$, and $\rho_{a}, \rho, \rho_{c}=0.02125,0.01500,0.01000,0.00500,0.00333$. Source: Authors.

\begin{tabular}{ccccccccccc}
\multicolumn{10}{c}{ Table 6. Fixing $b=30 \mathrm{~cm}$, and $\rho_{a}, \rho_{2} \rho_{c}=0.02125,0.01500,0.01000,0.00500,0.00333$. Source: Authors. } \\
\hline$b$ & $A_{s 1}$ & $A_{s 2}$ & $A_{s 3}$ & $d_{a}$ & $d$ & $d_{c}$ & & & & \\
$c m$ & $c^{2}$ & $c m^{2}$ & $c m^{2}$ & $c m$ & $c m$ & $c m$ & $\rho_{a}$ & $\rho$ & $\rho_{c}$ & $C_{t}$ \\
\hline 30 & 45.58 & 45.11 & 53.93 & 71.49 & 70.77 & 84.59 & 0.02125 & 0.02125 & 0.02125 & $6.91 C_{c}$ \\
30 & 37.05 & 36.68 & 43.84 & 82.33 & 81.51 & 97.42 & 0.01500 & 0.01500 & 0.01500 & $6.41 C_{c}$ \\
30 & 29.51 & 29.21 & 34.91 & 98.36 & 97.37 & 116.38 & 0.01000 & 0.01000 & 0.01000 & $6.18 C_{c}$ \\
30 & 20.38 & 20.17 & 24.11 & 135.84 & 134.48 & 160.73 & 0.00500 & 0.00500 & 0.00500 & $6.46 C_{c}$ \\
30 & 16.51 & 16.34 & 19.54 & 165.10 & 163.44 & 195.35 & 0.00333 & 0.00333 & 0.00333 & $6.99 C_{c}$ \\
\hline
\end{tabular}

Table 7. Fixing $b=30,40,50,60,70 \mathrm{~cm}$, and $d_{a}, d, d_{c}$ are equal (constant cross section). Source: Authors.

\begin{tabular}{cccccccccccc}
\hline$b$ & $A_{s 1}$ & $A_{s 2}$ & $A_{s 3}$ & $d_{a}$ & $d$ & $d_{c}$ & & & & \\
$c m$ & $c^{2}$ & $c m^{2}$ & $c m^{2}$ & $c m$ & $c m$ & $c m$ & $\rho_{a}$ & $\rho$ & $\rho_{c}$ & $C_{t}$ \\
\hline 30 & 25.83 & 25.28 & 37.42 & 110.02 & 110.02 & 110.02 & 0.00783 & 0.00766 & 0.01134 & $6.33 C_{c}$ \\
40 & 29.85 & 29.21 & 43.24 & 95.22 & 95.22 & 95.22 & 0.00784 & 0.00767 & 0.01135 & $7.30 C_{c}$ \\
50 & 33.40 & 32.68 & 48.37 & 85.13 & 85.13 & 85.13 & 0.00785 & 0.00768 & 0.01137 & $8.16 C_{c}$ \\
60 & 36.60 & 35.81 & 53.01 & 77.68 & 77.68 & 77.68 & 0.00785 & 0.00768 & 0.01137 & $8.94 C_{c}$ \\
70 & 39.54 & 38.69 & 57.28 & 71.90 & 71.90 & 71.90 & 0.00786 & 0.00769 & 0.01138 & $9.66 C_{c}$ \\
\hline
\end{tabular}

\section{Results}

Tables 2, 3 and 4 show the results of example 1 . Table 2 shows the results fixing $b=30,40,50,60,70 \mathrm{~cm}$. Table 3 shows the results fixing $b=30 \mathrm{~cm}$, and $\rho_{a}, \rho, \rho_{c}=0.02125,0.01500,0.01000,0.00500,0.00333$. Table 4 shows the results fixing $b=30,40,50,60,70 \mathrm{~cm}$, and $d_{a}, d, d_{c}$ are equal. For Table 2 the following is observed: when $b$ increases, the steel areas $A_{s 1}, A_{s 2}, A_{s 3}$ increase, the effective deeps $d_{a}, d, d_{c}$ decrease, the percentages of reinforcing steel $\rho_{a}$, $\rho_{c}$ slightly increase, and $\rho$ is constant, and the total cost $C_{t}$ increases. For Table 3 the following is observed: when $b$ remains constant and the percentages of reinforcing steel $\rho_{a}, \rho, \rho_{c}$ decrease, the steel areas $A_{s 1}, A_{s 2}, A_{s 3}$ decrease, the effective deeps $d_{a}, d, d_{c}$ increase, and the total cost $C_{t}$ decreases until $5.38 C_{c}$ and subsequently increases. For Table 4 the following is observed: when $b$ increases and $d_{a}, d, d_{c}$ are constant, the steel areas $A_{s 1}, A_{s 2}, A_{s 3}$ increase, the percentages of reinforcing steel $\rho_{a}, \rho, \rho_{c}$ increase, and the total cost $C_{t}$ increases.

Tables 5, 6 and 7 show the results of example 2. Table 5 shows the results fixing $b=30,40,50,60,70 \mathrm{~cm}$. Table 6 shows the results fixing $b=30 \mathrm{~cm}$, and $\rho_{a}, \rho, \rho_{c}=0.02125,0.01500,0.01000,0.00500,0.00333$. Table 7 shows the results fixing $b=30,40,50,60,70 \mathrm{~cm}$, and $d_{a}, d, d_{c}$ are equal. For Table 5 the following is observed: when $b$ increases, the steel areas $A_{s 1}, A_{s 2}, A_{s 3}$ increase, the effective deeps $d_{a}, d, d_{c}$ decrease, the percentages of reinforcing steel $\rho_{a}, \rho_{c}$ slightly increase, and $\rho$ is constant, and the total cost $C_{t}$ increases. For Table 6 the following is observed: when $b$ remains constant and the percentages of reinforcing steel $\rho_{a}, \rho, \rho_{c}$ decrease, the steel areas $A_{s 1}, A_{s 2}, A_{s 3}$ decrease, the effective deeps $d_{a}, d, d_{c}$ increase, and the total cost $C_{t}$ decreases until $6.18 C_{c}$ and subsequently increases. For Table 7 the following is observed: when $b$ increases and $d_{a}, d, d_{c}$ are constant, the steel areas $A_{s 1}, A_{s 2}, A_{s 3}$ increase, the percentages of reinforcing steel $\rho_{a}, \rho, \rho_{c}$ increase, and the total cost $C_{t}$ increases.

Figure 3 shows the trends of the steel area that is observed in Tables 2 and 5. 
Figure 3. Trends of the steel area of the Tables 2 and 5. Source: Authors.

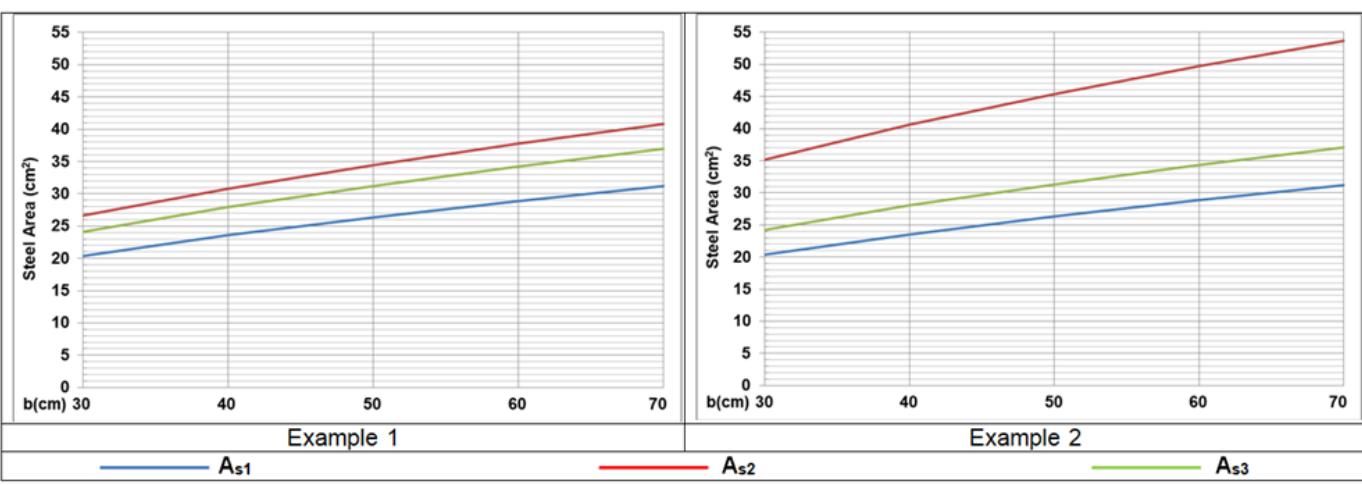

Figure 4 shows the trends of the effective depth that is observed in Tables 2 and 5.

Figure 4. Trends of the effective depth of the Tables 2 and 5. Source: Authors.

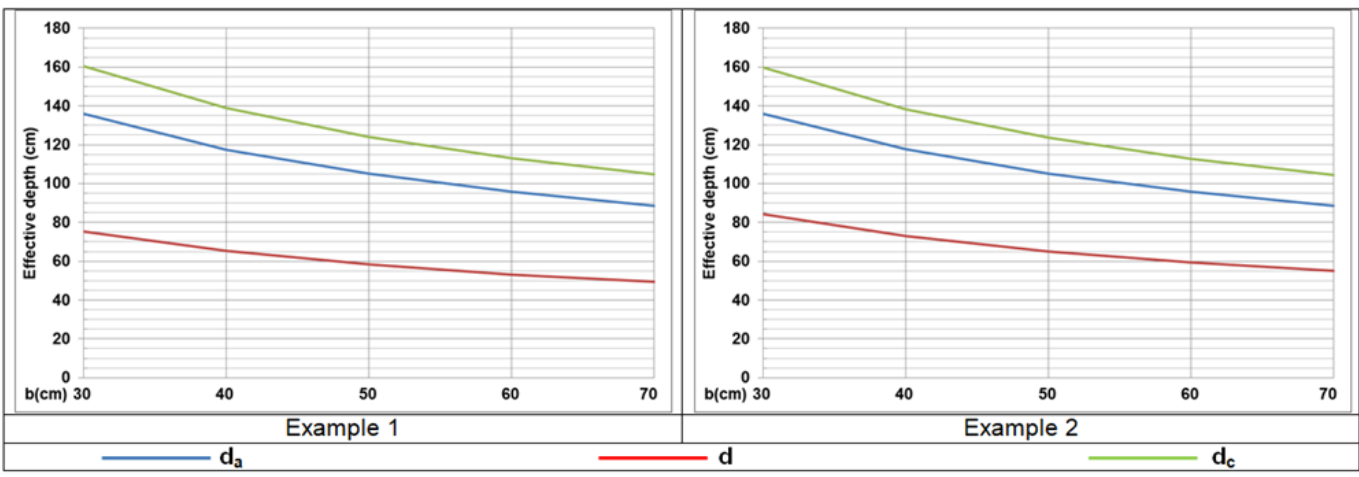

Figure 5 shows the trends of the percentage of reinforcing steel that is observed in Tables 2 and 5.

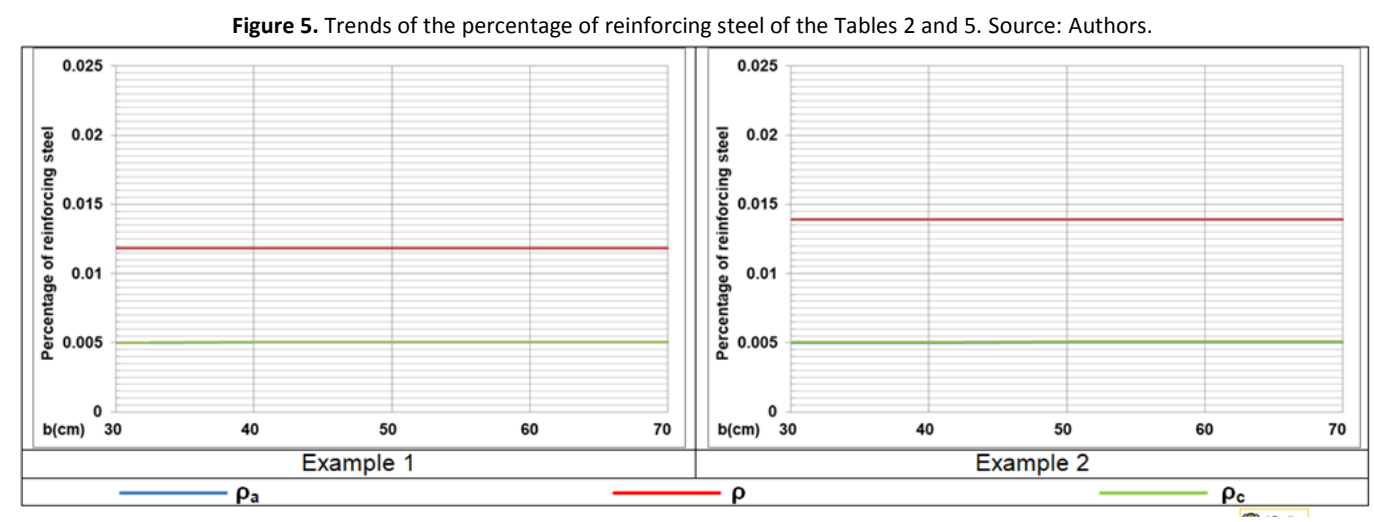

Figure 6 shows the trends of the steel area that is observed in Tables 3 and 6.

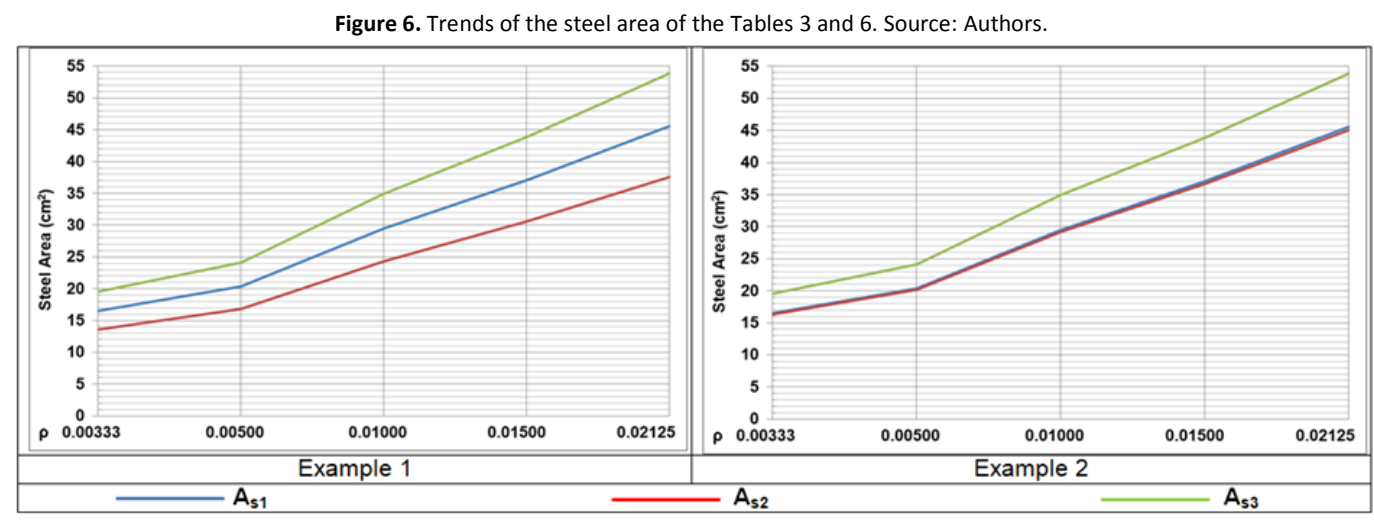


Figure 7 shows the trends of the effective depth that is observed in Tables 3 and 6.

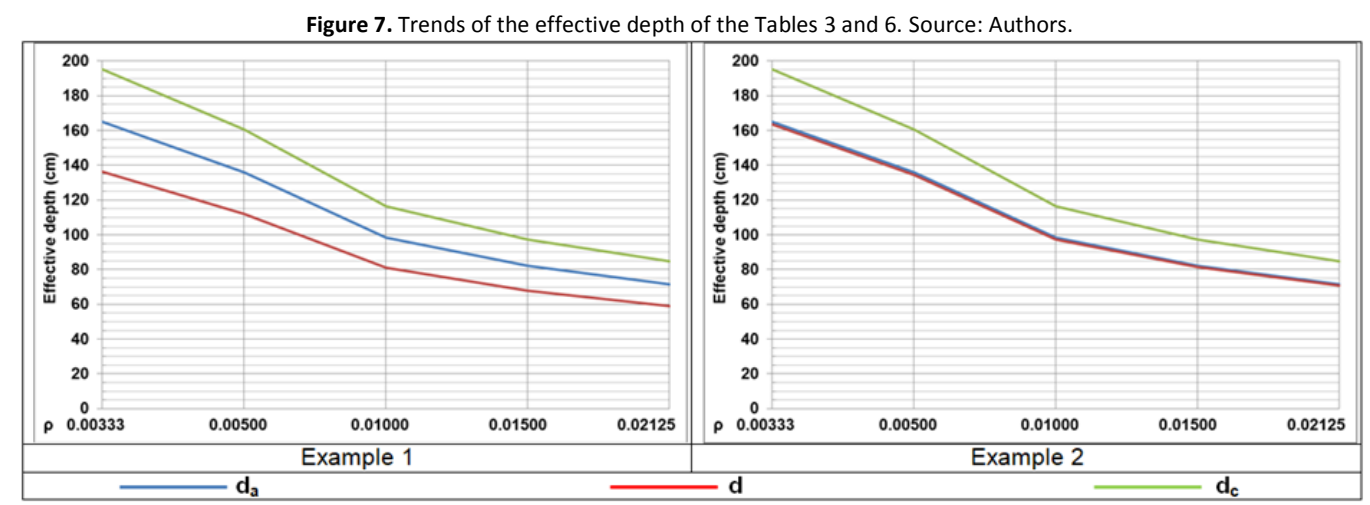

Figure 8 shows the trends of the steel area that is observed in Tables 4 and 7.

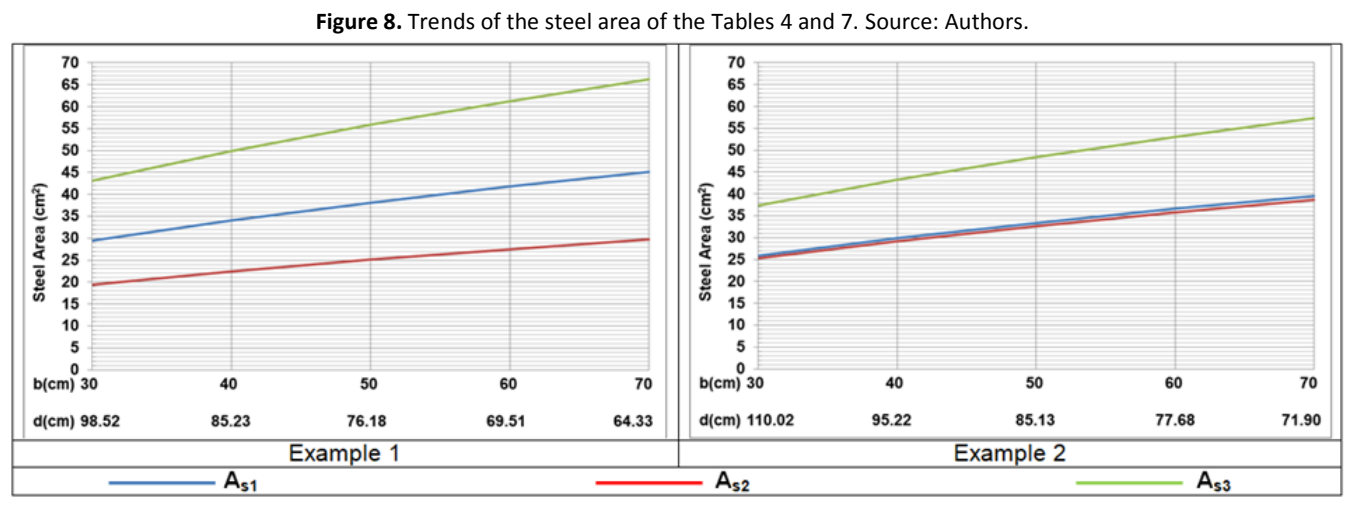

Figure 9 shows the trends of the percentage of reinforcing steel that is observed in Tables 4 and 7.

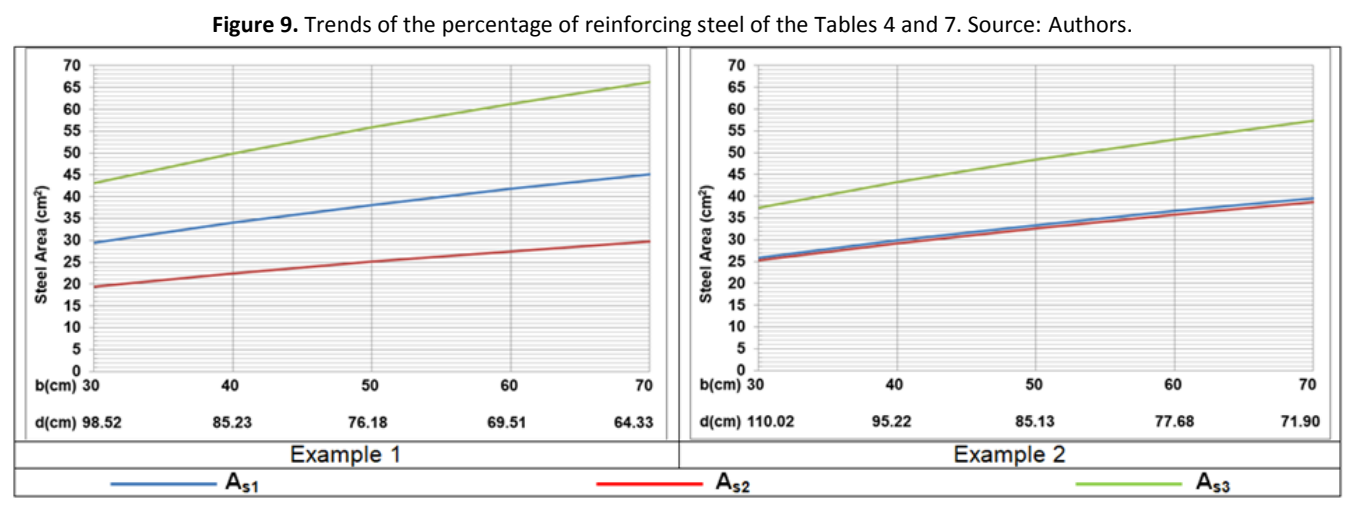

Figure 10 shows the comparison with respect to the total cost based on the number of times of the concrete cost of the beam subjected to a uniformly distributed load (Example 1) of Table 2 (Non-prismatic beam) and Table 4 (Prismatic beam), and the comparison with respect to the total cost based on the number of times of the concrete cost of the beam subjected to a concentrated load located to $3.00 \mathrm{~m}$ from support A (Example 2) of Table 5 (Nonprismatic beam) and Table 7 (Prismatic beam).

Now, the corresponding values are substituted into Eq. (25) to obtain the total volume of the beam. Consider $\mu=3$ which is the ratio of the weight of reinforcing steel to the weight of the concrete, and substituting into Eq. (27) to find the total weight of the beam.

Table 8 shows the comparison between the cost, volume, and weight of the non-prismatic beam and the prismatic beam of the example 1 (Uniformly distributed load). 


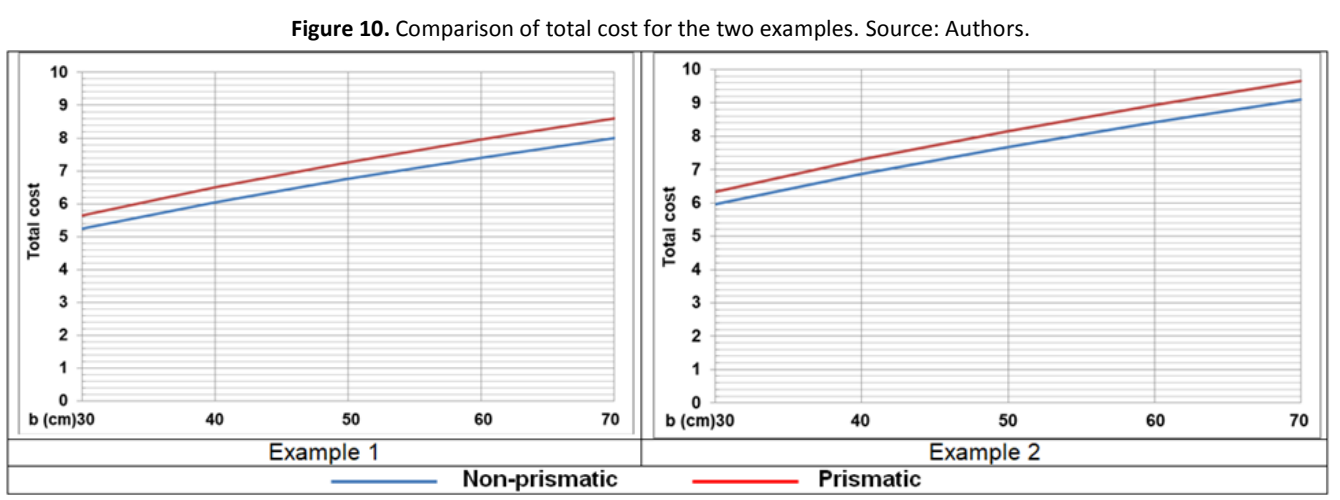

Table 8. Comparison for uniformly distributed load. Source: Authors.

\begin{tabular}{|c|c|c|c|c|c|c|c|c|c|}
\hline \multirow{2}{*}{$\begin{array}{c}\mathrm{b} \\
\mathrm{cm}\end{array}$} & \multicolumn{3}{|c|}{ Total cost } & \multicolumn{3}{|c|}{$\begin{array}{c}\text { Total volume } \\
\mathrm{m}_{3} \\
\end{array}$} & \multicolumn{3}{|c|}{ Total weight } \\
\hline & NPB & PB & PB/NPB & NPB & PB & PB/NPB & NPB & PB & $\mathrm{PB} / \mathrm{NPB}$ \\
\hline 30 & $5.25 C_{c}$ & $5.65 C_{c}$ & 1.08 & 2.82 & 3.08 & 1.09 & $2.88 W_{c}$ & $3.13 W_{c}$ & 1.09 \\
\hline 40 & $6.05 C_{c}$ & $6.51 C_{c}$ & 1.08 & 3.28 & 3.57 & 1.09 & $3.34 \mathrm{~W}_{\mathrm{c}}$ & $3.64 W_{c}$ & 1.09 \\
\hline 50 & $6.76 C_{c}$ & $7.27 C_{c}$ & 1.08 & 3.69 & 4.01 & 1.09 & $3.76 W_{c}$ & $4.08 W_{c}$ & 1.09 \\
\hline 60 & $7.41 C_{c}$ & $7.97 C_{c}$ & 1.08 & 4.06 & 4.41 & 1.09 & $4.13 W_{c}$ & $4.49 W_{c}$ & 1.09 \\
\hline 70 & $8.01 C_{c}$ & $8.61 C_{c}$ & 1.07 & 4.40 & 4.78 & 1.09 & $4.48 W_{c}$ & $4.87 W_{c}$ & 1.09 \\
\hline
\end{tabular}

Table 9 shows the comparison between the cost, volume, and weight of the non-prismatic beam and the prismatic beam of the example 2 (Concentrated load).

Table 9. Comparison for concentrated load. Source: Authors.

\begin{tabular}{|c|c|c|c|c|c|c|c|c|c|}
\hline \multirow{2}{*}{$\begin{array}{c}\mathrm{b} \\
\mathrm{cm}\end{array}$} & \multicolumn{3}{|c|}{ Total cost } & \multicolumn{3}{|c|}{$\begin{array}{c}\text { Total volume } \\
\mathrm{m}_{3} \\
\end{array}$} & \multicolumn{3}{|c|}{ Total weight } \\
\hline & NPB & PB & PB/NPB & NPB & PB & PB/NPB & NPB & PB & PB/NPB \\
\hline 30 & $5.96 C_{c}$ & $6.33 C_{c}$ & 1.06 & 3.23 & 3.42 & 1.06 & $3.29 W_{c}$ & $3.49 W_{c}$ & 1.06 \\
\hline 40 & $6.87 C_{c}$ & $7.30 C_{c}$ & 1.06 & 3.75 & 3.97 & 1.06 & $3.82 W_{c}$ & $4.04 W_{c}$ & 1.06 \\
\hline 50 & $7.68 C_{c}$ & $8.16 C_{c}$ & 1.06 & 4.21 & 4.46 & 1.06 & $4.29 W_{c}$ & $4.54 W_{c}$ & 1.06 \\
\hline 60 & $8.41 C_{c}$ & $8.94 C_{c}$ & 1.06 & 4.64 & 4.90 & 1.06 & $4.72 W_{c}$ & $4.99 W_{c}$ & 1.06 \\
\hline 70 & $9.09 C_{c}$ & $9.66 C_{c}$ & 1.06 & 5.03 & 5.31 & 1.06 & $5.12 W_{c}$ & $5.41 W_{c}$ & 1.06 \\
\hline
\end{tabular}

For Table 8 the following is observed: the prismatic beams have a total cost of the $8 \%$ greater with respect to the nonprismatic beams, and also the prismatic beams have a total volume and a total weight of the $9 \%$ greater with respect to the non-prismatic beams (see example 1).

For Table 9 the following is observed: the prismatic beams have a total cost, a total volume and a total weight of the $9 \%$ greater with respect to the non-prismatic beams (see example 2 ).

Conclusions

In the present work a methodology has been presented to evaluate the optimal design for beams of rectangular cross section with straight haunches (symmetrical or not symmetrical).

This research shows two practical examples of the proposed model. Example 1 considers a uniformly distributed load $w=150 \mathrm{kN} / \mathrm{m}$ on the beam. Example 2 considers a concentrated load $P=1000 \mathrm{kN}$ applied at a distance $e=3.00 \mathrm{~m}$ from support $A$.

The main conclusions are:

1.- For a smaller width $b$, the optimal design for both models is presented (see Tables 2 and 5 ).

2.- Non-prismatic beams are more economical with respect to prismatic beams (see Figs 4 and 5, Tables 8 and 9). The non prismatic beams for uniformly distributed load have a cost of $92.59 \%$, and for concentrated load have a cost of $94.34 \%$ with respect to the prismatic beams. 
3.- Non-prismatic beams have less volume with respect to the prismatic beams (see Tables 8 and 9). The non prismatic beams for uniformly distributed load have a volume of $91.74 \%$, and for concentrated load have a volume of $94.34 \%$ with respect to the prismatic beams.

4.- Non-prismatic beams have less weight with respect to the prismatic beams (see Tables 8 and 9). The non prismatic beams for uniformly distributed load have a weight of $91.74 \%$, and for concentrated load have a weight of $94.34 \%$ with respect to the prismatic beams.

The conclusions presented above are only for the examples presented in this document, and in other optimization situations, different conclusions can be obtained.

Other advantages of the non-prismatic beams on the prismatic beams are:

1.- The beams with haunches are cheaper than the beams of constant section.

2.- The beams with haunches are lighter than the beams of constant section, therefore the members that support these beams must be more economical and can have greater savings in the materials.

Therefore the formulation of the proposed model (optimal design) should be as follows:

1.- The known parameters are: Moments applied in the supports $\left(M_{A B}\right.$ and $\left.M_{B A}\right)$ are obtained from a structural analysis; Transverse loads to the beam ( $w$ and/or $P, e$ ); Total length of the beam $(L)$; Resistance of the materials that take part in the construction $\left(f_{y}\right.$ and $\left.f_{c}^{\prime}\right)$.

2.- From Table 1 are obtained: $V_{A}, V_{B}, M_{x}, a, c, x_{\max }, M_{\max }$ for each type of load. Parameters $a$ and $c$ are the distances of the haunches and are made to coincide with the inflection points.

3. The objective function is obtained by substituting the parameters $L, a, c, r$ into Eq. (18).

4.- The constraint functions are found by substituting the parameters $M_{A B}, M_{\max }, M_{B A}, \emptyset_{f}, f_{y}, f_{c}^{\prime}$ into Eqs. (19) to (26).

5.- If the objective function and the constraint functions are defined, the width $b$ of the beam must be fixed according to the code ( $\mathrm{ACl} 318 \mathrm{~S}-14)$.

Future research suggestions may be:

1.- Take into account the cost of the formwork

2.- Vary the values of the beam span, the load, the position of the concentrated load, $\alpha$ (ratio of the cost of steel to the cost of concrete).

References

American Concrete Institute (2014). Building Code Requirements for Structural Concrete and Commentary, Committee 318.

Barros, M.H.F.M., Martins, R.A.F. \& Barros, A.F.M. (2005). Cost optimization of singly and doubly reinforced concrete beams with EC2-2001. Structural and Multidisciplinary Optimization, 30, 236-242.

Bhalchandra, S.A. \& Adsul, P.K. (2012). Cost Optimization of Doubly Reinforced Rectangular Beam Section. International Journal of Modern Engineering Research, 2(5), 3939-3942.

Brown, C. (1984). Approximate stiffness matrix for tapered beams. Journal Structural Engineering-ASCE, 110(12), 3050-3055.

Ceramic, B. \& Fryer, C. (2000). Sensitivity analysis and optimum design curves for the minimum cost design of singly and doubly reinforced concrete beams. Structural and Multidisciplinary Optimization, 20, 260-268.

Chutani, S. \& Singh, J. (2017). Design optimization of reinforced concrete beams. Journal of The Institution of Engineers (India): Series A, 98(4), 429435.

Guldan, R. (1956). Estructuras aporticadas y vigas continuas. El ateneo. Buenos Aires, Argentina.

Hisham Ajmal P.C. (2017). A study on cost optimized structural design of reinforced concrete beams. International Journal of Scientific \& Engineering Research, 8(11), 7-11.

Just, D. (1977). Plane frameworks of tapering box and I-section. Journal Structural Engineering ASCE, 103(1), pp. 71-86., 103(1), 71-86.

Luévanos-Rojas, A. (2015). Modelado para vigas de sección transversal "I" sometidas a una carga uniformemente distribuida con cartelas rectas. Ingeniería Mecánica Tecnología y Desarrollo, 5(2), 281-292.

Luévanos-Rojas, A., López-Chavarría, S. \& Medina-Elizondo, M. (2016a). Modelling for mechanical elements of rectangular members with straight haunches using software: part 1. International Journal of Innovative Computing, Information and Control, 12(3), 973-985.

Luévanos-Rojas, A., López-Chavarría, S. \& Medina-Elizondo, M. (2016b). Modelling for mechanical elements of rectangular members with straight haunches using software: part 2. International Journal of Innovative Computing, Information and Control, 12(4), $1027-1041$. 
Luévanos-Rojas, A. (2016). Numerical experimentation for the optimal design of reinforced rectangular concrete beams for singly reinforced sections. Dyna, 83(196), 134-142.

Luévanos-Rojas, A., López-Chavarría, S. \& Medina-Elizondo, M. (2018). Optimización de vigas de concreto reforzado para secciones rectangulares con experimentos numéricos. Computación y Sistemas, 22(2), 599-606.

Medwadowski, S. (1984). Nonprismatic shear beams. Journal Structural Engineering-ASCE, 110(5), $1067-1082$.

Portland Cement Association (1958). Beam factors and moment coefficients for members of variable section, Handbook of frame constants. Chicago, IL, USA.

Schreyer, H. (1978). Elementary theory for linearly tapered beams. Journal Structural Engineering-ASCE, 104(3), 515-527.

Shooshtari, A. \& Khajavi, R. (2010). An efficient procedure to find shape functions and stiffness matrices of nonprismatic Euler-Bernoulli and Timoshenko beam elements. European Journal of Mechanics - A/Solids, 29(5), 826-836.

Rahmanian, I., Lucet, Y. \& Tesfamariam, S. (2014). Optimal design of reinforced concrete beams: A review. Computers and Concrete, $13(4), 457-482$.

Tena-Colunga, A. (1996). Stiffness formulation for nonprismatic beam elements. Journal Structural Engineering-ASCE, 122(12), 1484-1489.

Thomas, S.M. \& Arulraj, G.P. (2017). Optimization of singly reinforced RC beams”, International Journal of Research-Granthaalayah, 5(2), $199-207$.

Yuksel, S. (2012). Assessment of non-prismatic beams having symmetrical parabolic haunches with constant haunch length ratio of 0.5 . Structural Engineering and Mechanics, 42(6), 849-866. 